3 Thilen A, Larsson A. Congenital adrenal hyperplasia in Sweden 1969-1986. Prevalence, symptoms and age at diagnosis. Acta Paediatr Scand 1990; 79: 168-75.

4 DiMartino-Nardi J, Stoner E, O'Connell A, et al. The effect of treatment on final height in classical congenital adrenal hyperplasia. Acta Endocrinol (Copenh) 1986; 279 (suppl): 305-14.

5 Klingensmith GJ, Garcia SC, Jones HW, et al. Glucocorticoid treatment of girls with congenital adrenal hyperplasia: effects on height, sexual maturation and ferhyperplasia: effects on height, sexual

6 Hurtig AL, Rosenthal IM. Psychological findings in early treated cases of female pseudohermaphroditism caused by virilizing congenital adrenal hyperplasia. Arch Sex Behav 1987; 16: 209-23.

7 Dittmann RW, Kappes ME, Kappes MH. Sexual behaviou in adolescent and adult females with congenital adrenal hyperplasia. Psychoneuroendocrinology 1992; 17: 153-70.
8 Mulaikal RM, Migeon CJ, Rock JA. Fertility rates in female patients with congenital adrenal hyperplasia due to 21 hydroxylase deficiency. $N$ Engl $₹$ Med 1987; 316: 178-82.

9 Prader A. Der Genitalbefund bein Pseudohermaphroditismus feminus des kongenitalen adrenogenitalen ditismus feminus des kongenitalen adrenogenitalen

10 Brook CGD. The management of clasical 231-43. adrenal hyperplasia due to 21 -hydroxylase deficiency. Clin Endocrinol 1990; 33: 559-67.

11 Hughes IA. The adrenal gland. In: Hughes IA, ed. Handbook of endocrine investigations in children. London: Handbook of endocrine inves

12 Money J, Lewis V. IQ genetics and accelerated growth: adrenogenital syndrome. fohns Hopkins Hospital Bulletin 1966; 118: 365-73.

13 Nass R, Baker S. Learning disabilities in children with congenital adrenal hyperplasia. $f$ Child Neurol 1991; 6: 306-12.

\title{
Is alternating hemiplegia a mitochondrial disease?
}

The syndrome of alternating hemiplegia of childhood (AHC) was first described in $1971^{1}$ and has usually been thought to be a variant of migraine. A recent report from Paris describes 22 children and is an excellent review of the clinical findings and differential diagnosis. ${ }^{2}$ The cardinal features are: (1) repeated episodes of hemiplegia affecting each side of the body in turn, and sometimes both together, and occurring at least once a month; (2) onset before the age of 18 months; (3) recovery from hemiplegia during sleep; (4) paroxysmal dystonia, nystagmus, and autonomic disturbance; and (5) non-paroxysmal choreoathetosis, ataxia, and global learning disorder. The French workers point out that some of the features of AHC are similar to those of MELAS (mitochondrial myopathy, encephalopathy, lactic acidosis, and stroke-like episodes) a known mitochondrial disorder.

A paper from Montreal (Douglas L Arnold and colleagues, Annals of Neurology 1993; 33: 604-7) provides evidence of mitochondrial dysfunction in AHC. They examined four children with the disease using magnetic resonance spectroscopy to measure phosphorus and its compounds in resting gastrocnemius muscle and found reduced phosphorylation potential (a measure of mitochondrial energy storage ability (as ATP)), reduced amounts of phosphocreatine, and increased amounts of inorganic phosphate and ADP.

The authors interpret their findings as indicating mitochondrial dysfunction in muscle. They state that they can not be sure whether this dysfunction is primary or secondary but suggest that the clinical features of AHC taken together with these findings are consistent with a primary disorder of mitochondrial function.

ARCHIVIST

1 Verret S, Steele JC. Alternating hemiplegia in childhood: a report of eight patients with complicated migraine beginning in infancy. Pediatrics 1971; 47: 675-80.

2 Bourgeois M, Aicardi J, Goutieres F. Alternating hemiplegia of childhood. $\mathfrak{f}$ Pediatr 1993; 122: 673-9. 